\title{
Recent Strategies for Automatic Generation Control of Power Systems With Diverse Energy Sources
}

\author{
Ashwini Kumar, Gautam Buddha University, Greater Noida, India \\ iD https://orcid.org/0000-0002-4149-5869 \\ Omveer Singh, Department of Electrical Engineering, Gautam Buddha University, Greater Noida, India
}

\begin{abstract}
This paper reveals automatic generation control (AGC) strategies of power systems including diverse power generating sources, and comprehensive literature review is also presented. These diverse energy sources considered conventional power sources like thermal, diesel, nuclear, etc. and renewable energy sources (RESs). RESs are solar energy, wind energy, hydro energy, etc. A variety of AGC schemes based on hard, soft, and artificially intelligent computation techniques are presented here. The benefits and limitations of these energy generating units are also shown in this article. In the present scenario, deregulation, smart micro-grid, and grid concept are also utilized with interconnection of the considered energy generating sources. The literature of this review article fulfills the gap of recent and previous decades' research work and provides future exploration in AGC techniques.
\end{abstract}

\section{KEYWORDS}

Artificially Intelligent, Automatic Generation Control, Conventional, Electric Vehicle, Micro Grid, Renewable Energy Sources, Smart Grid, Soft Computing Techniques

\section{INTRODUCTION}

For modern power systems, frequency must be constant. The frequency variation is not acceptable in current power system for worldwide. Frequency is very important for multi-area power generating sources interconnected with hybrid resources. Automatic generation control of power systems, voltage-frequency play a major role as both voltage and frequency should be properly controlled. Load Frequency Control (LFC) maintains the stable frequency for a demand level after disturbance in load connected to different area. The contribution of power exchange for different load areas are controlled by LFC in the power systems. The quality power supply can be achieved through the help of AGC for multi-area interconnected power systems with diverse energy sources. As robust power demand is a need of mankind globally, when load penetrates from its defined value with perturbation, the state of the system can change from normal to abnormal condition. AGC must identify the deviation in frequency and maintained it to constant system frequency. As the operation of interconnected power systems should be balanced between generated powers with total load demand plus system losses.

DOI: 10.4018/IJSDA.20211001.oa8

This article published as an Open Access article distributed under the terms of the Creative Commons Attribution License (http://creativecommons.org/licenses/by/4.0/) which permits unrestricted use, distribution, and production in any medium, provided the author of the original work and original publication source are properly credited. 
If operating point differ the system frequency can deviates, cumulative cause shows unbalanced power in the exchange of areas, result may undesirable effect (Elgered, 2016; Kothari, \& Nagrath, 2009; Ibraheem, Kothari, \& Kumar, 2005). A single variable called as Area Control Error (ACE) is a combination of two variables one is frequency, another is tie-line power exchange. Many good ideas reflected by researchers for AGC problem, through the design of AGC regulators for uncertainty or variation, load characteristics, excitation control and other link like Alternating Current (AC)/Direct Current (DC) (Cohn, 1957; Elgerd, \& Fosha,1970; Quazza,1971; Calvoic, 1971; Quazza, 1966).

In the last decade, the modern concept for AGC like Artificial Neural Network (ANN), Genetic Algorithm (GA), and Fuzzy Logic Algorithm (FLA) is used to make our AGC simple and robust, as thermal power plant associating with solar energy in Photovoltaic (PV) modules, wind turbine, plug-in Electric Vehicle (EV), micro-grid, smart grid, and Super Conducting Magnetic Energy Storage (SMES) (Ross, 1966; Kalman, 1964; Yu, Vongsuriya, \& Wedman, 1970). This review paper (Kumar, 2019) gave a brief exploration of recent research articles written by various authors/ researchers/technocrats used different techniques of Artificial Intelligence (AI) and Soft Computing (SC) techniques. A good number of articles are reviewed and the modern AI with SC techniques used for AGC in which different algorithms are like Ant Colony Optimization (ACO) (Jagatheesan, Dey, Anand, \& Ashour, 2015), Bacteria Foraging Optimization Algorithm (BFOA) (Arya, \& Kumar, 2016), Differential Evolution (DE)-Particle Swarm Optimization (DEPSO) (Singh, 2017; Sahu, Panda, \& Pati, 2014), Gravitational Search Algorithm (GSA) (Kumar, et al., 2017; Khadanga, et al., 2017), Grey Wolf Optimizer (GOW) Algorithm (Saikia, et al., 2015; Guha, et al., 2016; Srinivasarathnam, et al., 2019; Padhy, et al., 2017; Aghaei, et al., 2013; Singh, et, al. 2017; Soni, et al., 2016; Abazari, et al., 2019), Firefly Algorithm/Hybrid Firefly Algorithm (FA/hFA) (Pradhan, et al., 2016; Padhana, et al., 2014; Chien, et al., 2011), Krill Herd Algorithm (KHA) (Guha, et al., 2016), Modified Grey Wolf Optimization (MGOW) (Aghaei, et al., 2013), Modified Harmony Search Algorithm (MHSA), Particle Swarm Optimization (PSO) (Nasiruddin, et al., 2012; Pathak, et al., 2018), Quasi-Oppositional Harmony Search Algorithm (QOHS) (Shiva, et al., 2015; Shiva, et al., 2016), Self Adaptive Modified Bat Algorithm (SAMBA), Teaching Learning Based Optimization (TLBO) (Sahu, et al., 2016), Whale Optimization Algorithm (WOA) (Hasanien, et al., 2018). These algorithms are justified by its authors with certain parameters, acceptability and also with their limitations.

\section{LITERATURE REVIEW}

\subsection{Motivation}

In research article, (Nasiruddin et al., 2012; Nasiruddin et al., 2016) showed as the load demand for different loading scenarios, the generators are interconnected by power line which increases the complexity of power system. Authors have been categorized the huge power systems with the principle of coherency for different control areas.

Additionally, research counted as complete power industry has put to operate in interconnected system due to exchange of pool operation for power systems. Modern power systems have most complex system when penetration occurs of RESs, utilization of smart grids, power system control by digitalization which may be hacked in Figure 1. (Alhelou et al., 2018) experimented on AGC in conventional, modern and future smart power system. Author's also selected power system operation, stability, and security issues.

Some researchers have been investigated for LFC in interconnected power systems; categorized as classical control method with Proportional (P), Proportional Integral (PI), PID and Proportional Integral Double Derivative (PIDD) controllers to control frequency and tie-line power flow, optimal control method, adaptive control system, intelligent control like FLA, AI based control and SC for AGC with various algorithms (Alhelou et al., 2018). 


\subsection{Power System Control: An Overview}

Kundur et al. (2004) defined completeness and robust power system as its initial condition always constant for both frequency and voltage, no deviation occur by deviating load demand. System should attain its stability with constant system frequency by any condition. In Figure 2, power system instability important phenomenon's is rotor angle instability, voltage instability, and frequency instability.

Large continuous control loop such as prime mover and excitation controls operate directly on generator units, and located at power plants. The continuous controls include generator excitation controls, prime movers control, reactive power controls, and High Voltage Direct Current (HVDC) controls and these are operating on-line. Additionally, these are linear, continuous active, and use local measurements (Bevrani et al. (2014).

In the Figure 3, frequency level control for power systems is represented. There is primary control for which governor-droop which results in steady state errors, secondary control in which the LFC or AGC (i): To control of interchange power with tie-lines for different control area. (ii): For maintaining the frequency into desirable range, and third tertiary control as ancillary reserve and re-dispatching units.

\section{CLASSIFICATION OF AGC SCHEMES}

Traditional power systems are run by burning fossil fuel energy source. The thermal power station, big hydro power plant, nuclear power plant and diesel power station are replaced by small hydro plant, solar park, wind turbine, plug-in EV, micro-grid, smart grid, ocean waves and tidal energy resource which are renewable and globally accepted also locally generated as well as utilized. The frequency of interconnected RES for power system should be fixed while for power exchange during peak load. In this paper, basically two type of classification with intelligent controller technique are: type 1 and type 2 in the Table1. Table 2, an analysis for referenced with system types and number of area used in AGC like single, two, three, and multi-area or islanded model, types of generating sources like thermal, hydro, solar, wind, EV, HVDC link, micro-grid, smart grid and PVs. Also with different types controller like FLA based PID, generation rate constraints (GRCs), generation dead band (GDB), Model Predictive Control (MPC), and other SC techniques like, PSO, GWO, BFO, ACO, DE, \& some other presented in the Table 1.

\subsection{TYPE -1}

In this section, references utilized for traditional frequency control as robust frequency control, multi-objective frequency control regulation, MPC, deregulated frequency control, and emergency condition in AGC.

\subsubsection{Robust Frequency Control}

For robust frequency control several optimization techniques were used and also their comparative analysis enhanced by different researchers with other optimization techniques and controllers like PSO, DEPSO, HDPSO, BFOA, and GA etc.

For AGC, Singh (2017) developed hybrid evolutionary algorithms (EA) and this hybrid EA algorithm can take used for dynamic curve performance with typical constraints that was precisely followed for their solutions. A novel Event Trigger Control (ETC) architecture designed by Dong et al.(2017) for LFC with primary PI controller and supplementary adaptive dynamic programming for future actions like updating and balancing etc., in a periodic structure. Hybrid control strategy proposed by (Jonshagen, \& Genrup, 2010) compiled by combining both sliding pressure control with semi arc control. 
Nayak et al. (2018) compared controller with and without derivative filter and conventional PID controller for AGC with two area thermal power system. Dorfler et al. (2017) examined on convex combination of the frequency measurements, followed by an integral control with a broadcast signal, also then optimally allocated at local generation units, local asymptotic stability of the closed-loop equilibrium of the considered power system model. Rout et al. (2012) analyzed, DE algorithm based PI controller for AGC of power system. Zhang et al. (2018) imposed a reduced-order model as singular perturbation arguments, put analytical expressions capturing the impact of the errors, and contain several case studies with different types of errors on a simplified New England/New York system model. Patel et al. (2018) performed to optimal AGC in the multi-area power system also tie-lines, with radial or ring for real time performance of power system. Pathak et al. (2018) worked for AGC for dynamic performance with two area thermal-thermal power system also worked for time constant versus generation schedule trajectories of steam chest time constant and re-heater time constant find for various control strategies of power output.

Benefits and Limitations

The controllers are utilized for most effective and robust performance and they overcome the parametric uncertainties. It has some limitations as below:

1. The performance of robust frequency control method for AGC of power systems with classical and adaptive control needs high precision for optimisation in multi-area and tile-line.

2. Requirement of deep knowledge and good skill for controlling techniques which is hard finding in most power systems.

\subsubsection{Robust Multi-Objective Frequency Control Regulation}

In this sub-section several optimization techniques discussed for used in AGC of power systems in multi-area like QOHS, hGGSA-PS, FOPI-FOPD, Biogeography based Optimization (BBO) \& hPSBBO, Stochastic Fractal Search (SFS), Emotional Reinforcement Learning (ERL), GWO, Crazy PSO (CPSO), hBFO-PSO, PSO with their compatibility also compared with other intelligent techniques used for AGC in power systems.

Dong et al. (2017) exhibited noble power flow models which ensure permission for multi-area AGC to maintain load for running generators, also worked separately with interconnected sub-area networks and represented the node power injection with power exchange for power flow model. Prostejovsky et al. (2018) introduced frequency controls those have both properties tuning less and quick responses with ensuring the monitoring for overall uncertainties which belong for power system to load. Saarinen et al. (2015) worked for; dynamic behavior of hydropower plants participating in primary frequency control is investigated also through frequency response, step response, and set point change tests on three Swedish hydropower plants resulted data are utilized for system identification of linear models combined with static nonlinearities. Rakhshani et al. (2017) developed a model to analyzed the dynamic effects with simulation by virtual synchronous power model participated active power loop control for multi-area power system in virtual synchronous power based HVDC link. A comparative performance assessment enhanced by (Shiva, et al., 2015), examined for QOHS algorithm and internal model control made for AGC. Li et al. (2016) experimented for system frequency with energy balance for control area for maintaining schedule exchange between control designs of distributed, low complexity generation and load control to achieve system-wide efficiency and robustness.

Ricatti-equation based AGC regulators developed by Sharma et al. (2016) for interconnected an AC/DC tie-line for two-area power system. The results were compared with finding of optimal AGC regulators also presented the effectiveness of the designed AGC regulators. Liang et al. (2017) created a model check efficiency problems and operational reliability of power systems with high wind power injected from frequency aspect. Knudsen et al. (2018) proposed design reduces the time-consuming 
task of regulator tuning also demonstrated improve transient frequency and voltage performance. Khadanga et al. (2017) established a multi-area interconnected power system with hGGSA-PS considering the nonlinear effect of Generation Rate Constraint (GRC). The proposed model reflected the superiority of simulation results with different performance index values and lesser settling time.

Rahman et al. (2016) developed a scheme for Governor Dead Band (GDB) and GRC for unequal four area thermal system with AGC. Also for PID, Two-degree of Freedom (2DOF)-PID and Three-degree of Freedom (3DOF)-PID as secondary controllers are implemented separately in the system. Pathak et al. (2016) utilized different generation schedules/levels operating thermal power system for AGC. Also, these plants made for different generation schedules and calculate steam turbine dynamic model parameters from an actual generating unit by using of data with heat balance. Lima et al. (2017) analyzed for simulator where the generators to be controlled by AGC. An Analysis which were computed from the frequency obtained by the physical model and economic analyzer compares the total production costs for the different analyzed scenarios also give feasible solutions. The conventional thermal system and dish sterling solar-thermal systems used separately and combination in AGC with geothermal power plant for interconnected system by (Tasnin, et al., 2018). Determination of robustness and sensitivity of optimum FOPI-FOPD controller gains and other parameters checked their normal value.

A comparative analysis done for BBO and hPS-BBO optimized 3DOF-PID controller by Rahman et al. (2016) also resulted better performance validated with random disturbance. Saha et al. (2017) made a controller to optimized parameters by SFS algorithm with integral-First Order Filter Effect (PDF) controller also analyzed the system robustness and its sensitivity. Bijami et al. (2017) experimented for power system with Lyapunov-Krasovskii and designed LMI-based delay-independent control law, also checked for load perturbation as a non-ideal communication network in both dropouts and variable delayed system. Mohanty et al. (2015) analyzed with optimum gains of Proportional Integral Double Derivative (PIDD) controller also it didn't required reset for variation of load side demand also sensitivity calculated by robustness for the system. Yu et al. (2015) created algorithm to coordinate information exchange and boost the multi-area control by Multiagent Reinforcement Learning Algorithm (MARL) which represented as Correlated Equilibrium Q $(\lambda)$ Learning (CEQ $(\lambda)$ ). Yin et al. (2017) presented a controller of a two-area load frequency control for AGC in power systems with Emotional Reinforcement Learning (ERL), including nine different methods of control schemes. Researchers presented by simulation as effectiveness of ERL over four Reinforcement Learning (RL) techniques and PI control. LFC in multi-area of AGC based on the cascade system and port-hamiltonian system PID controller by (Cai, et al., 2017) also comparative analysis confirmed its goodness over classical method. Halimi et al. (2018) pointed for Multi-Dimensional Analysis of Reactor Safety (MARS) model used for different types of systems with complete nuclear power plants also author worked for three different case analyzed in research and the variation of output power reference.

Saikia et al. (2011) developed a robust controller which can work for wide range variation in reheat coefficient, reheat time constant, system loading condition, inertia, size, and position of stepload perturbation constant with Integral Double Derivative (IDD) controller gains. Ibarra et al. (2014) discussed for generation ramp rates, GDBs, and speed droop characteristics analysis also produced the test result by field tests on thermal units. Ramakrishna et al. (2007) obtained a optimum controller gain for Automatic Load Frequency Control (ALFC) also integrated the impact on the system by transient performance, using GA with indices Integral Time Absolute Error (ITAE), Integral Square Error (ISE), and thermal and gas power generations and performance of the continuous system. Sharma et al. (2015) made PID controller with GWO optimization also used data like peak overshoot, settling time, and magnitude of oscillations in the system, with or without solar thermal power plant (STPP). Padhy et al. (2017) showed effectiveness of SFS algorithm over other intelligent technique for optimal control, teaching learning based optimization (LPO), and DE techniques simulation results have been compared for the identical power plants. 
Kaliannan et al. (2016) written a technique effectively analyze by adding non-linearity and boiler dynamics into the same investigated power system also performed comparison of the power system with/without non-linearity. Pradhan et al. (2016) used FA for optimization of PID in AGC where comparison shows the better one over GSA and GA, Authors also mention the impact of SMES and Unified Power Flow Controller (UPFC). Hota et al. (2014) used DE algorithm based PI \& PID controller for AGC of interconnected power system also shown the superiority over CPSO and study for more power source of units such as thermal, hydro, wind and diesel generating units for GRC and GDB of nonlinear.

Apostolopoulou et al. (2014) pointed for allocated power of unit with AGC analyzed the price for quality of AGC service among three different allocation methods. Kothari et al. (2012) presented a performance of the proposed controller, compared the effect of GRC on frequency deviation response with complete feedback controller. Arya et al. (2016) developed for interconnected via AC/DC parallel links with two equal control areas with hydro and thermal generating power sources. Authors made the CRAZYPSO and hBFOA-PSO algorithms for optimal PI regulators in AGC with two-area nonreheat thermal power system and GDB nonlinearity. Padhana et al. (2014) proposed a FA for LFC of multi-area power systems and compare it with other intelligent technique like BFOA, DE, and hBFOA-PSO optimized PI controller's performance developed FA-optimized PID controller. Nanda et al. (2015) utilized a PSO technique for delay in the ACE and the secondary controller. By selecting optimum weights in the cost function made an important aspect for AGC performance.

\section{Benefits and Limitations}

It has many implementations in bulk load consumers and industrial also there is need of more research as it satisfies the LFC in ground reality. There are various limitations of this control technique as below:

1. The performance of robust multi objective control based frequency control method for AGC of power systems with ACE, GRC, ISE and ITAE need a high precision for optimisation in two area, multi-area also needs more sophisticate with handling as hybrid energy resources penetration in convention system.

2. Use of SMES and Battery Energy Storage System (BESS) in AGC of power systems need properly tuning as in the above worked by researcher.

\subsubsection{Model Predictive Control Scheme Based AGC}

For this sub-section articles included with different AI techniques like PSO, Fractional Particle Swarm Optimization Memetic Algorithm (FPSOMA), Consensus Transfer Q-learning (CTQ) learning, \& MARL. Also used Secondary Frequency Regulation (SFR), Software based Self Test (SBST), BESS, GWO, Quasi-oppositional Grey Wolf Optimization Algorithm (QOGWO), \& KHA have used and their comparative analysis with their suitability and effectiveness was verified.

McNamara et al. (2018) introduced for frequency regulation in AC/Multi-terminal Direct Current (MTDC)-connected grids, proposed article for MPC as a means of implementing AGC, while minimizing DC grid power losses. M'zoughi et al. (2018) made model by using of PSO algorithm with FPSOMA to control of the oscillating water column based wave energy for high power output of the Nereida power plant. Zhang et al. (2018) explained CTQ learning for Generation Command Dispatch (GCD) of AGC. CTQ is a fully cooperative MARL, as not required an accurate mathematical model which is suitable for decentralized GCD with complex constraints and nonlinear objective function.

Guo et al. (2018) presented decentralized SFR is good for the expanding power systems. Rotor Angle Droop (RAD) control can autonomously restore the system frequency without the intervention 
of a dispatching centre, resulted more convenient for distributed generation (like PV) to participate in frequency regulation. Riefert et al. (2016) evaluated for SBST techniques which develop SBST programs itself completed manufacturing and load test which also proved superiority than manual techniques. Liu et al. (2016) proposed load-side controller with two roles firstly, to have fast systemlevel compensation to the disturbance and help the generators to restore the frequency quickly and secondly, to have a minimum impact on end users. Xiaorong et al. (2018) enhanced using BESS for frequency regulation to improve the AGC performance of grid connected generators. BESS can correct the deviation between the generator output and the AGC command quickly and effectively.

Vicuna et al. (2018) explained robust Low Voltage Ride Through (LVRT) control strategy gave the power delivery capabilities of the inverter-based Direct Power Generation System (DPGS) under voltage sags. The goodness of the utilized control strategy has been validated by the evaluation, which demonstrates the fulfillment of this control objective. Ersdal et al. (2016) planned a system model of the Nordic power system by using MPC based also justified its limitations for capacity of generation, tie-line power flow, and rate change of generation. Guha et al. (2016) validated the QOGWO method for their work by comparing its simulation outcome with GWO and other AI techniques. Abraham et al. (2007) proved a modified AGC by adding a small SMES unit for one or both areas it showed its effectiveness as SMES set made well integration both the areas and gave better dynamic performances for optimum flow of power when load disturbance in either of the areas. Guha et al. (2016) worked for optimization technique called KHA, and observed as KHA could reach optimal solution irrespective of the large variation with a faster convergence rate. Ganger et al. (2018) examined unbalanced load and generation play vital role when large amounts of renewable generation are being integrated in power systems.

\section{Benefits and Limitations}

It has many implementations in bulk load consumers and industrial also there is need of more research as it satisfies the AGC in ground reality. It has some limitations of this control technique as below:

1. The performance of model predictive control of frequency control used for power systems with deep integration of variable generation of hybrid energy resources required even good research.

2. This control for SMES and BESS in AGC of power systems need properly tuning as in the above view by researchers.

\subsubsection{AGC in Deregulated Environment}

In deregulated environment use of Demand Side Control (DSC) strategy, Sugeno fuzzy-logic (SFL), QOHS discussed in AGC of power systems. Authors tried to eye-lined the effectiveness of deregulated environment is suitable for AGC in power system.

Hu et al. (2017) presented DSC strategy for coordinating multiple load aggregators, i.e., aggregated responsive loads, to provide frequency regulation services. Simulation of plotted a leader-following communication protocol was considered for the load aggregators in which there was a centralized and multiple load aggregators. In paper (Ghafouri, \& Milimonfared, 2015) concept of micro-grids are becoming more popular and frequency control of power systems made such a way it might responsible to compensate load changes therefore by increasing penetration of Distributed Energy Resources (DERs) on system load analyzed. Simulated results for 9-bus power system in PSCAD software provided effectiveness of suggested scheme helped power system stability. Shiva et al. (2015) presented SFL technique with QOHS algorithm for AGC and gave consequences on bilateral policy/ dynamics. This method arranged good dynamic responses for wide range variation of system parameter. 
Persis et al.(2018) worked for optimal LFC scheme with power network of energy function developed nonlinear model of network which ahs quality of distinguished between load buses and generator.

Pourmousavi et al. (2014) demonstrated demand response for power system when dynamic performance analyzed for frequency control of system. Authors gave a scheme to balance this gap by demand response control loop of traditional LFC with single-area power system. Authors verified with simulation analysis for the effectiveness of the utilized method. Xu et al. (2016) represented with dynamic gain-tuning control method to frequency regulation of AGC in power system made a significant enhancement in AGC gain tuning. Development of an optimization technique (Barisal, Panigrahi, \& Mishra, 2017) for PID controller in AGC with hybrid PSO in Levy flight algorithm (LFPSO) also proved a robust system as free from disturbance and other technical deviated parameters. Mohanty et al. (2015) examined for control of GRC and AC/DC link with hydro, nuclear and reheat thermal as multi-source in deregulated AGC of power system.

Sahu et al. (2015) worked for deregulated environment AGC of power systems and developed PID filter. This analysis was completed for controller and scaled with different operating conditions for deregulated power demand market. Shiva et al. (2016) simulated decentralized control of AGC for power systems with three area power system showed analysis on price-based market operation. Bakken et al. (1998) presented a model for power systems based on classical LFC of area control error for interconnected power systems of Norway and Sweden.

\section{Benefits and Limitations}

Deregulated control performed better than centralized ones. It has some limitations that are:

1. This article presents decentralized control strategies as complete flow of power varies by multiarea connected with the tie-lines. There is a discussion for improvement in the power system stability and security for deregulated environment.

2. Cyber-attack issue must be avoided for upcoming with deregulated and its related modern AGC schemes which should be hack-proof system for complete power systems.

\subsubsection{Emergency Conditions in AGC}

Emergency condition occurs in AGC as several uncertainties due to penetration of RESs with conventional generation unit for multi-area. Some needful work examined by several researches and technocrats tried to point out security related issues and provide their fitted solution in research work as use of computer and internet being used for communication and other data transmission in AGC of power systems.

Apostolopoulou et al. (2015) programmed to eliminate the uncertainties with renewable generating sources, also error and noise with communication channels for AGC. Authors obtained expression for probability distribution functions also validate with Monte Carlo simulations. Huang et al. (2018) developed on line scrutiny with algorithm to detect cyber hacking on physical and statistical data of power systems. Saarinen et al. (2018) implemented balancing power and frequency control reserved were growing, by variable renewable production, which made new incomes but also a challenge made for operation with risky as reduced life time for controllable power plants. Alpcan et al. (2015) programmed a game-theoretic approach to smart grid security by combining quantitative risk management techniques with decision making on protective measures at the centre of the ongoing smart grid evolution increased its operational efficiency, for better susceptible to malicious attacks such as false data injection to electronic monitoring systems.

Hooshyar et al. (2018) False Data Injection Attacks (FDIAs) introduced a technique of AGC to compare non-optimal operation or unstable of the power grid. Moawwad et al. (2018) provided an algorithm for droop coefficients of generating units in hybrid AC-DC networks. Nguyen et al. (2017) 
developed to find attacks for AGC measurement as it made deviation in data which lead to error also a theft also made for loads or generators, leading to blackouts and potentially costly equipment damage. Peng et al. (2017) investigated a resilient event-triggering H1 LFC for multi-area power systems with energy-limited Denial-of-Service (DoS) attacks. They used the Lyapunov theory; two stability and stabilization criteria for the multi-area power systems are derived under consideration of the exergy limited DoS attacks. Adibhatla et al. (2014) took benefits include significant reduction in the Boiler Feed Pump (BFP) power consumption, reduction in exergy destruction associated with control valve throttling leading to improved energetic efficiency of all turbine sections and exergy destruction in BFP.

\subsection{Type-2}

This section concludes impact of injection of RESs with traditional power generating unit developed unbalanced frequency and maintain the constant frequency is quite difficult. The AGC of power systems in multi-area interconnected with diverse source maintain the regulation of frequency. Diverse sources like wind energy, solar PV cell, plug in EVs, micro-grid, smart grid, and other RESs are being used, the AGC play its role to maintain constant frequency.

\subsubsection{Impact of Renewable Energy in Frequency Regulation}

Hasanien (2018) presented control strategy in the AGC loops as PID controller, which was optimally designed by WOA. In this article, RES uncertainties with penetration for AGC in power system. Authors implemented hybrid DEPSO optimized fuzzy PID controllers, and two-area power systems with diverse sources of hydro, thermal and gas sources and GA used to obtain the optimal PID gains for various test cases using ISE plus ITAE performance index for fitness evaluation (Sahu, et al., 2014; \& Ramakrishna, et al., 2010).

An analysis on different nominal loading conditions due to step load disturbances in the system of transient responses has been checked. Pathak et al. (2015) found the effect of system parameters on optimum controller gains for discrete data AGC of an interconnected power system. Panda et al. (2016) designed PIDD controller using TLBO algorithm for AGC in power systems for multi-area with diverse energy sources. Gupta et al. (2014) demonstrated a multi-area AGC scheme with RES suitable in a restructured interconnected power system has been proposed. Wind turbine and PV generating unit integrated with the grid. Jagatheesan et al. (2015) made ACO algorithm for AGC based power system using ITSE and the Integral Time Absolute Error (ITAE) for three area unequal interconnected hydro, wind, and thermal power generating units. Zhao et al. (2018) worked for model predictive AGC method which included as geographical variation and injection of RESs in modern power system showed negative. Hasanien (2015) made for enhancement of the LVRT capability of gridconnected PV power plants with continuous mixed-norm algorithm based adaptive control strategy.

\subsubsection{AGC Scheme in Wind Energy Source}

The application of AGC for wind energy as there is much deviation of wind speed in a year and injection of wind energy with power grid. In research article, ( $\mathrm{Li}, \& \mathrm{Xu}, 2016)$ researched for regulation and control of frequency of power system with AGC for variable wind energy with PI control to make desired output. Watson et al. (2018) demonstrated working of grid-tied battery storage energy system and wind park for AGC. Yan et al. (2016) plotted deviation of voltage level by injecting high wind energy to power system deviate frequency. Improvement achieved by pilot bus selection and the partitioning method for improved the performance of Automatic Voltage Control (AVC). The data table on the New England 39-bus system tabulated the effectiveness of the identified approaches. Hasanien et al. (2017) created symbiotic Symbiotic Organisms Search (SOS) algorithm for in optimally designed PID controllers for AGC in multi-area power systems incorporating wind farms with non-linearity and uncertainty. 
Lee et al. (2017) introduced a coordinated Distributed Model Predictive Control (DMPC) for the LFC of a power system that incorporates inherently variable wind-power generations. DMPC communicates power system measurement and prediction data, and considers the information of other controllers for their local objective to realize effective coordination. Green et al. (2015) utilized for DC link energy storage with Variable Structure Controller (VSC)-HVDC link to store kinetic energy from turbine run with wind energy as frequency control and system inertia to an AC network. Hadley et al. (2015) paper worked for comparison of frequency control of wind impact for wind model and non-wind model with consideration of increasing active governor capacity and reducing GDB action. Basit et al. (2014) enhanced the security and the reliability of a power system operation with bulk wind power penetration by coordinated control strategy for the AGC.

\subsubsection{Frequency Control in Micro-Grids}

This sub-section contains considerable points as technical issues when micro-grid interconnected with grid system or operated as islanded mode the need of maintaining constant system frequency. Some authors worked for micro-grid interconnected with grid system or islanded conditions. In paper, Zang et al. (2016) performed for typical cyber-physical micro-grid system. The traditional diesel generator and inverter-interfaced made the system very complicated. The components of cyber with communication network and computer system connected with DGs, used to process and send required data to controllers. This system introduced for controllability, observibility and stabilization for micro-grid, the cyber and physical components need to be integrated. Zhongwen et al. (2016) worked for smart grid, with integration of RESs worked with control strategies like primary droop control, second AGC, and tertiary economic dispatch, used for controlled and optimized a micro-grid.

Martí et al. (2017) worked for islanded micro-grid system with secondary control that switches between two configurations according to a time-dependent protocol. The designed model based on improving the performance and control schemes with no communications transient response and frequency restoration. Shafiee et al. (2017) gave a decentralized control strategy for the voltage regulation of islanded inverter-interfaced micro-grids with plug and play functionality of distributed Generators. John et al. (2015) experimented for cooperative control, with use of localized controller's data for communication for collectively operation of secondary control actions.

Thought for primary, secondary and tertiary control with hierarchical architecture of power systems and researched for flexibility and performance with averaging based distributed controller's communication among the generation units (Dörfler, et al, 2016; Simpson-Porco, et al., 2017). Velasco et al. (2018) worked with digital communication network for real-time data exchange of frequency and voltage restoration control policies and tertiary control for micro-grid and grid. The problem for stabilizing voltages resolved by (Tucci, \& Riverso, 2018) for DC micro-grids with interconnection of Distributed Generation Units (DGU), power lines, and loads. Consideration of decentralized control network as primary controller of each DGU can be designed in a plug and play fashion, permitted the seamless addition of new DGUs. Patterson et al. (2015) developed a model working with cost effectiveness for hybrid grid-tied micro-grid with combination of solar PV, batteries, and fuel cell systems.

Kumar et al. (2015) analyzed challenges in the micro-grid and its important issues related to the micro-grid were its, autonomous operation, control strategies, regulatory barriers and protection in islanding operation which are being discussed. Kayalvizhi et al. (2017) established LFC of an isolated micro-grid with fuzzy adaptive model predictive control and proved its efficacy. Kumar et al. (2019), evaluated the Maximum Power Point Tracking (MPPT) tracker and also for maximum electrical efficiency. Srinivasarathnam et al. (2019) analyzed Grey Wolf Optimization (GWO) algorithm for optimal tuning of PID controller gains used in secondary frequency control of an autonomous microgrid system and the multi-microgrid system operates in isolation. 


\subsubsection{AGC Based Electric Vehicle}

The prime algorithm for injection of EVs as Vehicle to Grid (V2G) and Grid to Vehicle (G2V) developed uncertainties in the power system. It is quite difficult to maintain grid frequency as people are using plug-in EV for different times as V2G and G2V. Here is some need full and experiment have performed by some researchers with appropriate algorithms and IA techniques like Lifelong Learning (LL), Artificial Bee Colony Optimisation (ABCO), PSO, and use of Dish-stirling Solar Thermal System (DSTS), GWO, First Order Proportional Integral Derivate (FOPID), Sine Cosine Algorithm (SCA) are utilized.

Zhang et al. (2018) presented a LL algorithm based Complementary Generation Control (CGC) of interconnected power grids with high penetration RESs and EVs. Oshnoei et al. (2019) researched for EVs with AGC for perturbation of multi-area. First time used of EVs with ABCO with tilt ID controller. Mathur et al. (2016) explored on integration with wind power and V2G for stable frequency by perturbation. Tie-line power oscillations reduced with adaptive PSO FLA based controller and used to suppress frequency. Dixit et al. (2019) announced transmission systems and AGC. EV connected with the system individually as well as in fleet (group of vehicles). The research for charging, discharging and power levels discussed in this article. Liu et al. (2018) developed two control strategies of AGC with EVs for fast response and adjustment of EVs. The signal derived from two high frequency regulator from ACE and digital filter with Area Regulation Requirement (ARR). Wenzel et al. (2017) instructed for bidirectional charging and discharging with AGC. In addition of MPC with bidirectional charging quality used to develop a real-time controller. Saha et al. (2019) explained for multi-area with time delay in AGC by integration of EVs and RESs.

Hiskens et al. (2009) explored utilizations of engaging plug-in (EVs) in system level grid operations for AGC, spinning reserve and economic dispatch/unit commitment. Almeida et al. (2010) worked on EVs to stabilize with AGC. Gaur et al. (2018) made a model consisting of a three area system embedded with EVs in all the three control areas along with DSTS in only area-1. Padhy et al. (2017) developed Modified GWO (MGWO) based optimal cascade PI-PD controller for AGC of power systems in plug-in EVs. Gaur et al. (2018) presented a frequency regulation scheme of a multi-source power system with the integration of RES and EVs. The application of 2DOF-PID controller and created optimization technique called as wind driven optimization for simultaneous optimization of the controller gains and parameters has been attempted. Khezri et al. (2018) made a smart structure for charging and discharging of EVs in bidirectional type controlled.

\subsubsection{AGC Based Smart Grid}

The sub-section covers information for Cognitive Radio (CR) networking for smart grid, another is Real Time Digital Simulator (RTDS), while MGWO also mirrored the effectiveness for AGC in power systems, other AI techniques used in this zone are GWO, DE, GSA, PSO, Ecological Population Cooperative Control (EPCC), Multi-agent System Stochastic Consensus Game (MAS-SCG), Policy Dynamics based Win or Learn Fast - Policy Hill Climbing $\lambda$ (PDWolf-PHC $(\lambda)$ ), \& Q-learning used. Also these techniques seen with system parameters and its suitability have been checked by investigators for their investigations.

Shichao et al. (2015) included CR networking technology in smart-grids for communication establishment purpose. Upreti et al. (2016) enhanced a smart system with automatic synchronize as several generator were connected to industrial load and run for islanded with multiple but different bus-tie also utility tie-breakers. Cheng et al. (2011) fitted a system with balanced frequency control for generation and demand occur simultaneously also by using of adaptive or AI applications to the controller design.

Panda et al. (2017) revealed MGWO based cascade PI-PD controller for AGC of power systems in presence of plug in EV. This algorithm qualified for four bench mark test functions and compared with original GWO, DE, GSA, and PSO to show its superiority. This study reveals that plug in EVs contribute in the AGC to control system frequency. Alizadeh et al. (2013) researched with RESs 
requires sophisticated planning and operation scheduling along with state of art technologies. Xi et al. (2018) explained EPCC based on the win-loss criterion and the time tunnel idea, can compute the win-loss criterion accurately and converge to Nash equilibrium rapidly.

\subsubsection{Some Recent Al Techniques in AGC}

This subsection presents other recent research algorithms and different techniques for making controller of AGC in power systems. It demonstrates AI like FA, GWO, GSA, DSC, MOF, PS, Sliding Mode Controller (SMC), Regulation Marginal Cost (RMC), ABC, and Fuzzy $H ¥$-Iterative Learning Controller (FILC).

Rajbongshi et al. (2017) established design of AGC with robust optimal controller. In AVR and LFC both used for AGC with GRC \& GDB in the three unequal areas with three sources like solar, thermal and diesel. IDD with D-Filter (IDDF) is identified for this combined AVR \& ALFC. A meta-heuristic as lightning search algorithm optimization technique is used. Jagatheesan et al. (2017), developed FA to optimize the PID controller in more than one area power system for reheat thermal and compared with GA and PSO based PID controller. Gupta et al. (2016) wrote GWO for AGC in two-area power system for primary governor loop. This process was being used both ISE and ITAE.

Singh et al. (2017) used GWO technique to optimize gains of three unequal area of AGC with reheat thermal system also doubly fed induction generator wind turbine. Mohanty et al. (2017) concreted two unequal areas with multiple hybrid-sources interconnected power system. Lal et al. (2016) used GWO algorithm with the fuzzy based PID controllers for interconnected hydro-thermal power system in AGC. Soni et al. (2016) represented system robustness of 2DOF-PID controller optimized by varying the parameters with standard test system, operating load, by size and location at unbalanced area. Abazari et al. (2019) investigated Multi-objective Function (MOF) with ABC algorithm produced work on RES for two-area power systems wind farm.

Rakhshani et al. (2016) worked for derivative control based virtual inertia for interconnected systems in the multi-area AGC system and used the stored energy of converter devices in AC/DC interconnected AGC. Hu et al. (2015) presented a distributed planning DSC strategy for coordinating multiple load aggregators, i.e., aggregated responsive loads, to provide frequency regulation services. Abazaria et al. (2019) presented a novel LFC model for a stand-alone hybrid micro-grid in the presence of RESs. Tan et al. (2017) calculated a BESS also minimizing the BESS's area with enhancing lifespan. Authors (Yin, et al., 2019; Khadanga, et al., 2017; \& Wu, et al., 2016) worked for interconnected systems with hybrid intelligent optimization techniques utilized in AGC. Zhang et al. (2017) utilized RMC technique with distributed coordination AGC as regulation capacity in different areas to remove frequency deviations. Ramlal et al. (2019) designed FILC is designed for decentralized LFC with little knowledge of the local power area's model and no knowledge of the external power area's models. Authors (Wei, et al., 2019; Campbell, et al., 2014; \& Monasterious, et al., 2017) also gave renewable energy penetration and energy storage for AGC.

Bouzaida \& Sakly (2018) developed to control for nonlinear systems control with neuro-fuzzy system by adaptive sliding mode controller. Salima et al. (2018) developed the global stability with nonlinear controller as the motor speed reference adjusted for the maximum power point (MPPT). Yatimi et al (2018) worked for incremental conductance MPPT technique for an off-grid PV system for variable climate conditions. Gholizad et al (2017) article focused on private players for deregulated energy market as this is need of today. Pham et al (2017) developed a time-delay system to generate double-scroll chaotic attractors irrespective of model and presented model suitability. Hirpara et al. (2020) worked for three first-order differential equations coupled with two algebraic equations for stochastic for wind speed, the wind turbine-generator system.A gain schedule PI fuzzy load frequency control (GLFC) with two area system (Elmenfy, 2020) tuned to worked in real time. 


\section{ANALYSIS}

Figure 4, Table $2 \&$ Table 3 gives the information about techniques covered in this research article at a glance. ACO, PSO, other-PSO, FA, GOW and QOHS are reflected many times in this article. GOW algorithm used for different controller for single-area, two-area, three-area, \& multi-area and hybrid energy resources interconnected with traditional power generating station. AGC in power systems can be handled better with PSO \& GWO which are mentioned through research articles.

\section{CONCLUSION}

The paper presents recent research done by different authors as different techniques used for the robust improvement of AGC with tie-line and integrated with hybrid sources. Due to importance, frequency response mathematical models of different power system types such as conventional and smart power system are studied. Although modern control approaches such as optimal control theory, robust control, and SC based control technique are reviewed for LFC in power systems. Some recent role of EVs, micro-grid, smart grid and other renewable source need more explored as when injection of these energy sources with main grid system so that maintained frequency deviation occur also the AGC play its role for multi-area power systems. 


\section{REFERENCES}

Abazari, A., Monsef, H., \& Wu, B. (2019). Load frequency control by de-loaded wind farm using the optimal fuzzy-based PID droop controller. IET Renewable Power Generation, 13(1), 180-190.

Abazaria, A., Monsefa, H., \& Wub, B. (2019). Coordination strategies of distributed energy resources including FESS, DEG, FC and WTG in load frequency control (LFC) scheme of hybrid isolated micro-grid. Elsevier. Electrical Power and Energy Systems, 109, 535-547.

Abraham, R. J., Das, D., \& Patra, A. (2007). Automatic generation control of an interconnected hydrothermal power system considering superconducting magnetic energy storage. Elsevier. Electrical Power and Energy Systems, 29, 571-579.

Adibhatla, S., \& Kaushik, S. C. (2014). Energy and exergy analysis of super critical thermal power plant at various load conditions under constant and pure sliding pressure. Applied Thermal Engineering, Elsevier, 73(1), 51-55.

Aghaei, J., \& Alizadeh, M. I. (2013). Demand response in smart electricity grids equipped with renewable energy sources: A review. Elsevier. Renewable \& Sustainable Energy Reviews, 18, 64-72.

Alhelou, H. H., Golshan, M. H. H., Zamani, R., Forushani, E. H., \& Siano, P. (2018). Challenges and opportunities of load frequency control in conventional, modern and future smart power systems: A comprehensive review. Energies, 11(2497), 1-35.

Ameli, A., \& Hooshyar, A. (2018). Attack detection for load frequency control systems using stochastic unknown input estimators. IEEE Transactions on Information Forensics and Security, 13(10).

Apostolopoulou, D., Domínguez-García, A. D., \& Sauer, P. W. (2015). An assessment of the impact of uncertainty on automatic generation control systems. IEEE Transactions on Power Systems, 1-9.

Apostolopoulou, D., Sauer, P. W., \& Dom'1nguez, A. D. (2014). Automatic Generation Control and its Implementation in Real Time. IEEE Computer society, 47th Hawaii International Conference on System Science.

Arya, Y., \& Kumar, N. (2016). AGC of a multi-area multi-source hydrothermal power system interconnected via AC/DC parallel links under deregulated environment. Elsevier. Electrical Power and Energy Systems, 75, 127-138.

Bakken, B. H., \& Grande, O. S. (1998). Automatic generation control in a deregulated power system. IEEE Transactions on Power Systems, 13(4), 1401-1406.

Bansal, R. C., Nasiruddin, I., Niazi, K. R., \& Sharma, G. (2016). Robust automatic generation control regulators for a two-area power system interconnected via $\mathrm{AC} / \mathrm{DC}$ tie-lines considering new structures of matrix $\mathrm{Q}$. IET Generation, Transmission \& Distribution, 10(14).

Barisal, A. K., Panigrahi, T. K., \& Mishra, S. (2017). A Hybrid PSO-LEVY flight algorithm based fuzzy PID controller for automatic generation control of multi area power systems: fuzzy based hybrid PSO for automatic generation control. International Journal of Energy Optimization and Engineering (IJEOE), 6(2), 42-63. doi: 10.4018/IJEOE.2017040103

Basit, A., Hansen, A. D., Altin, M., Sørensen, P., \& Gamst, M. (2014). Wind power integration into the automatic generation control of power systems with large-scale wind power. IET J Eng, 2014(10), 538-545.

Bendtsen, J. D., \& Knudsen, J. (2018). Supervisory control implementation on diesel-driven generator sets. IEEE Transactions on Industrial Electronics, 65(12).

Bevrani, H. (2014). Robust power system frequency control. Springer.

Bhatti, T. S., \& Ramakrishna, K. S. S. (2007). Sampled-data automatic load frequency control of a single area power system with multi-source power generation. Electric Power System Components, 35, 955-980.

Bhongade, S., Tyagi, B., \& Gupta, H. O. (2014). Multi-Area Automatic Generation Control Scheme including Renewable Energy Sources. TELKOMNIKA Indonesian Journal of Electrical Engineering, 12(7), 5052-5070.

Bijami, E., \& Farsangi, M. M. (2017). Networked distributed automatic generation control of power system with dynamic participation of wind turbines through uncertain delayed communication network. IET Renewable Power Generation, 11(8). 
Bouzaida, S., \& Sakly, A. (2018). Adaptive Neuro-Fuzzy Sliding Mode Controller. International Journal of System Dynamics Applications, 7(2), 34-54. doi:10.4018/IJSDA.2018040103

Cai, L., Hu, H., \& He, Z. (2017). A new load frequency control method of multi-area power system via the viewpoints of Port-Hamiltonian system and cascade system. IEEE Transactions on Power Systems, 32(3), 1689-1700.

Calvoic, M. (1971). Linear regulator design for a load and frequency control. IEEE PES, 2271-2285.

Campbell, T., \& Bradley, T. H. (2014). A model of the effects of automatic generation control signal characteristics on energy storage system reliability. Elsevier. Journal of Power Sources, 247, 594-604.

Cao, J., \& Hu, J. (2017). Improving frequency stability based on distributed control of multiple load aggregators. IEEE Transactions on Smart Grid, 8(4).

Chakraborty, T., \& Watson, D. (2018). Automatic generation control using an energy storage system in a wind park. IEEE Transactions on Power Systems, 33(1).

Chien, L. R. C., Wu, Y. S., \& Cheng, J. S. (2011). Online estimation of system parameters for artificial intelligence applications to load frequency control. IET Generation, Transmission \& Distribution, 5(8), 895-902.

Cohn, N. (1957). Some aspects of tie-line bias control on interconnected power systems. Amer. Inst. Elect. Eng. Trans., 75, 1415-1436.

Dixit, A., \& Sharma, V. (2019). A comprehensive review on vehicle to grid (V2G) operation in power system network. International Journal for Scientific Research \& Development, 7(2).

Domínguez-García, A. D., \& Zhang, J. (2018). On the impact of measurement errors on power system automatic generation control. IEEE Transactions on Smart Grid, 9(3).

Dong, L., Tang, Y., \& He, H. (2017). An Event-Triggered Approach for Load Frequency Control with Supplementary ADP. IEEE Transactions on Power Systems, 32(1), 581-589.

Dong, X., \& Sun, H. (2017). Power flow analysis considering automatic generation control for multi-area interconnection power networks. IEEE Transactions on Industry Applications, 53(6).

Dörfler, F., \& Grammatico, S. (2017). Gather-and-broadcast frequency control in power systems. Elsevier. Automatica, 79, 296-305.

Dörfler, F., \& Simpson-Porco, J. W. (2016). Breaking the hierarchy: distributed control and economic optimality in microgrids. IEEE Transactions on Control of Network Systems, 3(3).

Elgerd, O. I., \& Fosha, C. (1970). Optimum megawatt frequency control of multi-area electric energy systems. IEEE Transactions on Power Apparatus and Systems, 89(4), 556-563. doi:10.1109/TPAS.1970.292602

Elgered, O. I. (2016). Electric Energy System Theory- An Introduction. New Delhi, India: McGraw Hill Education (India) Pvt Ltd.

Elmenfy, T. H. (2020). Gain schedule pi fuzzy load frequency control for two-area electric power system: load frequency control. International Journal of Energy Optimization and Engineering (IJEOE), 9(3), 39-50. doi:10.4018/IJEOE.2020070103

Ersdal, A. M., Imsland, L., \& Uhlen, K. (2016). Model predictive load-frequency control. IEEE Transactions on Power Systems, 31(1), 777-785.

Fu, B., He, J., He, L., Xu, G., \& Zhao, X. (2018). A system compensation based model predictive agc method for multiarea interconnected power systems with high penetration of PV system and random time delay between different areas. Hindawi, Mathematical Problems in Engineering.

Ganger, D., \& Zhang, J. (2018). Forecast-based anticipatory frequency control in power systems. IEEE Transactions on Power Systems, 33(1).

Gaur, P., Bhowmik, D., \& Soren, N. (2018). Impact assessment of vehicle-to grid in frequency control of multiarea hybrid system. IACSIT International Journal of Engineering and Technology, 7, 120-125. 
Gaur, P., Soren, N., \& Bhowmik, D. (2018). Secondary Frequency Regulation of Multi-area Interconnected Hybrid Power System with Electric Vehicle. International Journal on Electrical Engineering and Informatics, 10(4), 738-752. doi:10.15676/ijeei.2018.10.4.8

Ghafouri, A., \& Milimonfared, J. (2015). Coordinated control of distributed energy resources and conventional power plants for frequency control of power systems. IEEE Transactions on Smart Grid, 6(1).

Gholizad, A., Ahmadi, L., Hassannayebi, E., Memarpour, M., \& Shakibayifar, M. (2017). A System Dynamics Model for the Analysis of the Deregulation in Electricity Market. International Journal of System Dynamics Applications, 6(2), 1-30. doi:10.4018/IJSDA.2017040101

Gorripotu, T. S., Sahu, R. K., \& Panda, S. (2015). AGC of a multi-area power system under deregulated environment using redox flow batteries and interline power flow controller. Elsevier, I. J. Engineering Science and Technology, 18, 555-578.

Guha, D., Roy, P. K., \& Banerjee, S. (2016a). Load frequency control of large scale power system using quasioppositional grey wolf optimization algorithm. Elsevier, I. J. Engineering Science and Technology, 19, 1693-1713.

Guha, D., Roy, P. K., \& Banerjee, S. (2016b). Krill herd algorithm for automatic generation control with flexible AC transmission system controller including superconducting magnetic energy storage units. IET J Eng, (5), $147-161$.

Guo, M., \& Wei, Q. (2018). New approach of automatic generation control based on absolute rotor angle droop control. IET Generation, Transmission \& Distribution, 12(14).

Gupta, E., \& Saxena, A. (2016). Grey wolf optimizer based regulator design for automatic generation control of interconnected power system. Cogent Engineering, 3(16), 1-20.

Halimi, B., \& Suh, K. Y. (2012). Engineering nonlinearity characteristic compensation for commercial steam turbine control valve using linked MARS code and matlab simulink. Nuclear Engineering and Design, Elsevier, $243,360-370$.

Hasanien, H. M. (2015). An adaptive control strategy for low voltage ride through capability enhancement of grid-connected photovoltaic power plants. IEEE Transactions on Power Systems, 1-8.

Hasanien, H. M. (2018). Whale optimisation algorithm for automatic generation control of interconnected modern power systems including renewable energy sources. IET Generation, Transmission \& Distribution, 12(3), 607-614.

Hasanien, H. M., \& El-Fergany, A. A. (2017). Symbiotic organisms search algorithm for automatic generation control of interconnected power systems including wind farms. IET Generation, Transmission \& Distribution, $11(7)$.

Hill, D. J., \& Liu, T. (2016). Non-disruptive load-side control for frequency regulation in power systems. IEEE Transactions on Smart Grid, 7(4).

Hiskens, I., \& Callaway, D. (2009). Achieving Controllability of Plug-in Electric Vehicles. IEEE, 1215-1220.

Hota, P. K., \& Mohanty, B. (2015). Comparative performance analysis of fruit fly optimisation algorithm for multi-area multi-source automatic generation control under deregulated environment. IET Generation, Transmission \& Distribution, 9(14).

Hu, J., Cao, J., Guerrero, J. M., Yong, T., \& Yu, J. (2015). Improving Frequency Stability Based on Distributed Control of Multiple Load Aggregators. IEEE Transactions on Smart Grid, 1-15.

Huang, T., \& Satchidanandan, B. (2018). An online detection framework for cyber attacks on automatic generation control. IEEE Transactions on Power Systems, 33(6).

Ibarra, J. J., Morales, M. I., \& Cabrera, W. J. (2014). AGC parameter determination for an oil facility electric system. IEEE Transactions on Industry Applications, 50(4), 2876-2882.

Ibraheem, K., Kumar, P., \& Kothari, D. P. (2005). Recent philosophies of automatic generation control strategies in power systems. IEEE Transactions on Power Systems, 20(1), 346-357. doi:10.1109/TPWRS.2004.840438 
Jagatheesan, K., Anand, B., Samanta, S., Dey, N., \& Ashour, A. S. (2017). Design of a proportional-integralderivative controller for an automatic generation control of multi-area power thermal systems using firefly algorithm. IEEE/CAA Journal of Automatica Sinica, 1-14.

Jagatheesan, K., Dey, N., Anand, B., \& Ashour, A. S. (2015). Artificial intelligence in performance analysis of load frequency control in thermal-wind-hydro power systems. International Journal of Advanced Computer Science and Applications, 6(7), 204-212.

Jonshagen, K., \& Genrup, M. (2010). Improved load control for a steam cycle combined heat and power plant. Energy, Elsevier, 35(4), 1694-1700.

Junyent-Ferré, A., Pipelzadeh, Y., \& Green, T. C. (2015). Blending HVDC-link energy storage and offshore wind turbine inertia for fast frequency response. IEEE Transactions on Sustainable Energy, 6(3), 1059-1066.

Kaliannan, J., Baskaran, A., Dey, N., \& Ashour, A. S. (2016). Ant colony optimization algorithm based PID controller for LFC of single area power system with non-linearity and boiler dynamics. World Academic Press. World Academic Union, 12(1), 3-14.

Kalman, R. E. (1964). When is a linear control system optimal. Journal of Basic Engineering, 51-60.

Kayalvizhi, S., \& Kumar, D. M. V. (2017). Load frequency control of an isolated micro grid using fuzzy adaptive model predictive control. IEEE Access : Practical Innovations, Open Solutions, 5, 16241-16251.

Khadanga, R. K., \& Satapathy, J. K. (2017). A hybrid gravitational search and pattern search algorithm for tuning damping controller parameters for a unified power flow controller-A comparative approach. WILEY. International Journal of Numerical Modelling, 1-21.

Khezri, R., Oshnoei, A., Hagh, M. T., \& Muyeen, S. M. (2018). Coordination of heat pumps, electric vehicles and AGC for efficient LFC in a smart hybrid power system via SCA-based optimized FOPID controllers. Energies, 11.

Kothari, D. P., \& Nagrath, I. J. (2009). Modern Power System Analysis. Tata McGraw Hill.

Kothari, D. P., Parmar, K. P. S., \& Majhi, S. (2012). Load frequency control of a realistic power system with multi-source power generation. Elsevier. Electrical Power and Energy Systems, 42, 426-433.

Kou, G., Till, M., \& Bilke, T. (2015). Primary frequency response adequacy study on the U.S. eastern interconnection under high-wind penetration conditions. IEEE Power and Energy Technology Systems Journal, 2(4), 125-134.

Kumar, A., \& Azad, M. L. (2015). Challenges in recent microgrid systems: A review. International Journal of Advances in Engineering and Technology, 8, 203-210.

Kumar, A., \& Khadanga, R. K. (2017). Hybrid adaptive 'gbest'-guided gravitational search and pattern search algorithm for automatic generation control of multi-area power system. IET Generation, Transmission \& Distribution, 11(13).

Kumar, A., \& Singh, O. (2019). Recent Strategies for Automatic Generation Control of Multi-Area Interconnected Power Systems. 2019 3rd International Conference on Recent Developments in Control, Automation \& Power Engineering (RDCAPE), (pp.153-158). doi: doi:10.1109/RDCAPE47089.2019.8979071

Kumar, A., Singh, O., \& Singh, M. (2019). Renewable Energy Sources Integration in Micro-grid including Load Patterns. 2019 3rd International Conference on Recent Developments in Control, Automation \& Power Engineering (RDCAPE), (pp.88-93). doi: doi:10.1109/RDCAPE47089.2019.8979036

Kundur, P., Paserba, J., \& Ajjarapu, V. (2004). Definition and classification of power system stability. IEEE Transactions on Power Systems, 92(2), 1387-1401.

Lal, D. K., Barisal, A. K., \& Tripathy, M. (2016). Grey wolf optimizer algorithm based fuzzy PID controller for AGC of multi-area power system with TCPS. Procedia Computer Science, 92, 99-105.

Law, Y. W., \& Alpcan, T. (2015). Security games for risk minimization in automatic generation control. IEEE Transactions on Power Systems, 30(1).

Li, F., \& Xu, Y. (2016). Dynamic gain-tuning control (DGTC) approach for AGC with effects of wind power. IEEE Transactions on Power Systems, 31(5). 
Li, F., Xu, Y., \& Jin, Z. (2016). Dynamic gain-tuning control (DGTC) approach for AGC with effects of wind power. IEEE Transactions on Power Systems, 31(5), 3339-3348.

Li, N., \& Zhao, C. (2016). Connecting automatic generation control and economic dispatch from an optimization view. IEEE Transactions on Control of Network Systems, 3(3).

Li, Q., \& Zhang, X. S. (2018). Consensus transferq-learning for decentralized generation command dispatch based on virtual generation tribe. IEEE Transactions on Smart Grid, 9.

Li, Z., \& Zang, C. (2016). MAS based distributed automatic generation control for cyber-physical microgrid system. IEEE/CAA Journal of Automatica Sinica, 3(1).

Li, Z., \& Zang, C. (2016). Agent-based distributed and economic automatic generation control for droop-controlled AC microgrids. IET Generation, Transmission \& Distribution, 10(14).

Liang, C., \& Wang, P. (2017). Operational reliability and economics of power systems with considering frequency control processes. IEEE Transactions on Power Systems, 32(4).

Lima, F. D., \& Lima, O. D. (2017). A simulator for the AGC function as a tool to decide the generators to be controlled by AGC. IEEE Latin America Transactions, 15(9).

Liu, H., Huang, K., Yang, Y., Wei, H., \& Ma, S. (2018). Real-time vehicle-to-grid control for frequency regulation with high frequency regulating signal. Protection and Control of Modern Power Systems, 3(13).

Liu, S., \& Liu, P. X. (2015). Modeling and stability analysis of automatic generation control over cognitive radio networks in smart grids. IEEE Transactions on Systems, Man, and Cybernetics. Systems, 45(2).

Liu, X., Zhang, Y., \& Lee, K. Y. (2017). Coordinated distributed MPC for load frequency control of power system with wind farms. IEEE Transactions on Industrial Electronics, 64(6), 5140-5150.

López, M. A. G., \& Vicuña, J. L. G. d. (2018). Control strategy for grid-connected three-phase inverters during voltage sags to meet grid codes and to maximize power delivery capability. IEEE Transactions on Power Electronics, 33(1).

M'zoughi, F., \& Bouallègue, S. (2018). Stalling-free control strategies for oscillating-water-column-based wave power generation plants. IEEE Transactions on Energy Conversion, 33(1).

Manson, S. M., \& Upreti, A. (2016). Case study: Smart automatic synchronization in islanded power systems. IEEE Transactions on Industry Applications, 52(2).

Marinelli, M., \& Prostejovsky, A. M. (2018). Tuningless load frequency control through active engagement of distributed resources. IEEE Transactions on Power Systems, 33(3).

Martí, P., \& Velasco, M. (2018). Performance evaluation of secondary control policies with respect to digital communications properties in inverter-based islanded microgrids. IEEE Transactions on Smart Grid, 9(3).

Mathur, H. D., \& Bhateshvar, Y. K. (2016). Frequency regulation with vehicle-to-grid (V2G) option in multigeneration power network. Energetika, 62, 68-77.

McGrath, B., Patel, R., Li, C., \& Yu, X. (2018). Optimal automatic generation control of an interconnected power system under network constraints. IEEE Transactions on Industrial Electronics, 65(9).

McNamara, P., \& Milano, F. (2018). Model predictive control-based AGC for multi-terminal HVDC-connected AC grids. IEEE Transactions on Power Systems, 33(1).

Moawwad, A., \& El-Saadany, E. F. (2018). Dynamic security-constrained automatic generation control (AGC) of integrated AC/DC power networks. IEEE Transactions on Power Systems, 33(4).

Mohanty, B., Acharyulu, B. V. S., \& Hota, P. K. (2017). Moth-flame optimization algorithm optimized dualmode controller for multiarea hybrid sources AGC system. Optimal Control Applications \& Methods, 1-15.

Mohanty, B., \& Hota, P. K. (2015). Comparative performance analysis of fruit fly optimisation algorithm for multiarea multisource automatic generation control under deregulated environment. IET Generation, Transmission \& Distribution, 9(14), 1845-1855. 
Mohanty, B., Panda, S., \& Hota, P. K. (2014). Differential evolution algorithm based automatic generation control for interconnected power systems with non-linearity. Alexandria Engineering Journal, 53, 537-552.

Monasterious, P. R. B., \& Trodden, P. (2017). Low-complexity distributed predictive automatic generation control with gurantteed properties. IEEE Transactions on Smart Grid. Advance online publication. doi:10.1109/ TSG.2017.2705524

Mou, L., Dong, Y., Wang, B., Guo, Y., Xue, F., \& Xie, X. (2018). Improving AGC performance of coal-fueled thermal generators using multi-MW Scale BESS: A practical application. IEEE Transactions on Smart Grid, 9(3).

Nanda, J., Mishra, S., \& Saikia, L. C. (2011). Performance comparison of several classical controllers in AGC for multi-area interconnected thermal system. International Journal of Electrical Power \& Energy Systems, $33,394-401$.

Nanda, J., Sharma, D., \& Mishra, S. (2015). Performance analysis of automatic generation control of interconnected power systems with delayed mode operation of area control error. IET J Eng, 4, 164-173.

Nasiruddin, I., \& Pathak, N. (2018). AGC of two area power system based on different power output control strategies of thermal power generation. IEEE Transactions on Power Systems, 33(2).

Nasiruddin, I., \& Singh, O. (2012). Design of particle swarm optimization (PSO) based automatic generation control (AGC) regulator with different cost functions. Journal of Electrical and Electronics Engineering Research, 4(2), 33-45.

Nasiruddin, I., \& Singh, O. (2016). Optimal AGC regulator for multi-area interconnected power systems with parallel AC/DC links. Cogent Engineering, Systems \& Control, 3.

Nayak, J. R., Shaw, B., \& Sahu, B. K. (2018). Application of adaptive-SOS (ASOS) algorithm based interval type-2 fuzzy-PID controller with derivative filter for automatic generation control of an interconnected power system. International Journal of Engineering Science and Technology, 21, 465-485.

Oshnoei, A., Khezri, R., Muyeen, S. M., Oshnoei, S., \& Blaabjerg, F. (2019). Automatic generation control incorporating electric vehicles. Electric Power Components and Systems. Advance online publication. doi:10. $1080 / 15325008.2019 .1579270$

Padhana, S., Sahu, R. K., \& Panda, S. (2014). Application of Firefly Algorithm for Load Frequency Control of Multi-area Interconnected Power System. Elsevier. Electrical Power and Energy Systems, 42(13), 1419-1430.

Padhy, S., \& Panda, S. (2017). A hybrid stochastic fractal search and pattern search technique based cascade PI-PD controller for automatic generation control of multi-source power systems in presence of plug in electric vehicles. Elsevier. CAAI Transactions on Intelligence Technology, 2, 12-25.

Padhy, S., Panda, S., \& Mahapatra, S. (2017). A modified GWO technique based cascade PI-PD controller for AGC of power systems in presence of Plug in Electric Vehicles. Engineering Science and Technology, an International Journal, 20, 427-442. doi: 10.1016/j.jestch.2017.03.004

Padhy, S., Panda, S., \& Mahapatra, S. (2017). A modified GWO technique based cascade PI-PD controller for AGC of power systems in presence of plug in electric vehicles. I. J. Engineering Science and Technology, an International Journal, 20, 427-442.

Panda, S., Sahu, R. K., \& Rout, U. K. (2012). Design and analysis of differential evolution algorithm based automatic generation control for interconnected power system. Ain Shams Engineering Journal, 1-13.

Pathak, N., Verma, A., \& Bhatti, T. S. (2015). Study the effect of system parameters on controller gains for discrete AGC of hydro-thermal system. 2015 Annual IEEE India Conference (INDICON), 1-5.

Pathak, N., Verma, A., \& Bhatti, T. S. (2016). Automatic generation control of thermal power system under varying steam turbine dynamic model parameters based on generation schedules of the plants. Journal of Engineering (Stevenage, England). Advance online publication. doi:10.1049/joe.2016.0178

Patterson, M., \& Macia, N. F. (2015). Hybrid microgrid model based on solar photovoltaic battery fuel cell system for intermittent load applications. IEEE Transactions on Energy Conversion, 30(1).

Peng, C., Li, J., \& Fei, M. (2017). Resilient event-triggering $H ¥$ load frequency control for multi-area power systems with energy-limited DoS attacks. IEEE Transactions on Power Systems, 99, 1-1. 
Pham, V., Volos, C., \& Vaidyanathan, S. (2017). A Chaotic Time-Delay System with Saturation Nonlinearity. International Journal of System Dynamics Applications, 6(3), 111-129. doi:10.4018/IJSDA.2017070106

Pourmousavi, S. A., \& Nehrir, M. H. (2014). Introducing dynamic demand response in the LFC Model. IEEE Transactions on Power Systems, 29(4), 1562-1571.

Pradhan, P. C., Sahu, R. K., \& Panda, S. (2016). Firefly algorithm optimized fuzzy PID controller for AGC of multi-area multi-source power systems with UPFC and SMES. I. J. Engineering Science and Technology, an International Journal, 19, 338-354.

Quazza, G. (1966). Non -interacting control of interconnected electric power systems. IEEE Transactions on Power Apparatus and Systems, 85(7), 727-741.

Quazza, G. (1971). Automatic control in Electric Power Systems. Automatica, 6(1), 123-150. doi:10.1016/00051098(70)90080-4

Rahman, A., Saikia, L. C., \& Sinha, N. (2016). Automatic generation control of an unequal four-area thermal system using biogeography-based optimised 3DOF-PID controller. IET Generation, Transmission \& Distribution, 10(16).

Rahman, A., Saikia, L. C., \& Sinha, N. (2016). Maiden application of hybrid pattern search-biogeography based optimisation technique in automatic generation control of a multi-area system incorporating interline power flow controller. IET Generation, Transmission \& Distribution, 10(7).

Rajbongshi, R., \& Saikia, L. C. (2017). Combined control of voltage and frequency of multi-area multisource system incorporating solar thermal power plant using LSA optimised classical controllers. IET Generation, Transmission \& Distribution, 11(10), 2489-2498.

Rakhshani, E., Remon, D., Cantarellas, A. M., \& Rodriguez, P. (2016). Analysis of derivative control based virtual inertia in multi-area high-voltage direct current interconnected power systems. IET Gener. Trans. Distrib., 1-12.

Ramakrishna, K. S. S., Sharma, P., \& Bhatti, T. S. (2010). Automatic generation control of interconnected power system with diverse sources of power generation. International Journal of Engineering Science and Technology, 2(5), 51-65.

Remon, D., \& Rakhshani, E. (2017). Virtual synchronous power strategy for multiple HVDC interconnections of multi-area AGC power systems. IEEE Transactions on Power Systems, 32(3).

Rey, J. M., \& Martí, P. (2017). Secondary switched control with no communications for islanded microgrids. IEEE Transactions on Industrial Electronics, 64(11).

Riefert, A., \& Cantoro, R. (2016). A flexible framework for the automatic generation of SBST programs. IEEE Transactions on Very Large Scale Integration (VLSI) Systems, 24(10).

Rocha Almeida, P. M., Peças Lopes, J. A., Soares, F. J., \& Vasconcelos, M. H. (2010). Automatic generation control operation with electric vehicles. 2010 IREP Symposium Bulk Power System Dynamics and ControlVIII(IREP) (pp. 1-7). doi: doi:10.1109/IREP.2010.5563295

Ross, C. W. (1966). Error adaptive control computer for interconnected power system. IEEE Transactions on Power Apparatus and Systems, 85(7), 742-749.

Saarinen, L., \& Norrlund, P. (2015). Field measurements and system identification of three frequency controlling hydropower plants. IEEE Transactions on Energy Conversion, 30(3).

Saarinen, L., \& Norrlund, P. (2018). Allocation of frequency control reserves and its impact on wear and tear on a hydropower fleet. IEEE Transactions on Power Systems, 33(1).

Sadabadi, M. S., \& Shafiee, Q. (2017). Plug-and-play voltage stabilization in inverter-interfaced microgrids via a robust control strategy. IEEE Transactions on Control Systems Technology, 25.

Saha A., \& Saikia, L. C. (2019). Renewable energy source-based multiarea AGC system with integration of EV utilizing cascade controller considering time delay. Int Trans Electr Energ Syst. doi: 10.1002/etep.2646 
Saha, D., \& Saikia, L. C. (2017). Automatic generation control of a multi-area CCGT-thermal power system using stochastic search optimised integral minus proportional derivative controller under restructured environment. IET Generation, Transmission \& Distribution, 11(15).

Sahu, B. K., Pati, S., \& Panda, S. (2014). Hybrid differential evolution particle swarm optimisation optimised fuzzy proportional-integral derivative controller for automatic generation control of interconnected power system. IET Generation, Transmission \& Distribution, 8(11), 1789-1800.

Sahu, R. K., Gorripotu, T. S., \& Panda, S. (2016). Automatic generation control of multi-area power systems with diverse energy sources using teaching learning based optimization algorithm. International Journal of Engineering Science and Technology, 19, 113-134.

Saikia, L., \& Sharma, C., Y. (2015). Automatic generation control of a multi-area ST - Thermal power system using Grey Wolf Optimizer algorithm based classical controllers. International Journal of Electrical Power \& Energy Systems, 73, 853-862.

Salima, M., Loubna, A., \& Riad, T. (2018). A Global Stability of Linearizing Control of Induction Motor for PV Water Pumping Application. International Journal of System Dynamics Applications, 7(3), 31-56. doi:10.4018/ IJSDA.2018070102

Shiva, C. K., \& Mukherjee, V. (2015). Comparative performance assessment of a novel quasi-oppositional harmony search algorithm and internal model control method for automatic generation control of power systems. IET Generation, Transmission \& Distribution, 9(11).

Shiva, C. K., \& Mukherjee, V. (2015). Automatic generation control of multi-unit multi-area deregulated power system using a novel quasi-oppositional harmony search algorithm. IET Generation, Transmission \& Distribution, 9, 1-11.

Shiva, C. K., \& Mukherjee, V. (2016). A novel quasi-oppositional harmony search algorithm for AGC optimization of three-area multi-unit power system after deregulation. I. J. Engineering Science and Technology, 19, 395-420.

Simpson-Porco, J. W., \& Dörfler, F. (2017). Voltage stabilization in microgrids via quadratic droop control. IEEE Transactions on Automatic Control, 62(3).

Simpson-Porco, J. W., Shafiee, Q., Dorfler, F., Vasquez, J. C., Guerrero, J. M., \& Bullo, F. (2015). Secondary frequency and voltage control of islanded microgrids via distributed averaging. IEEE Transactions on Industrial Electronics, 62(11).

Singh, A., Nautiyal, B., \& Naresh, R. (2017). Grey wolf optimizer based PI-PD cascade controller for automatic generation control of integrated wind-thermal power system. Journal of Energy Research and Environmental Technology, 4(2), 139-144.

Singh, C. J. A., Rocke, S., \& Sutherland, M. (2019). Decentralized Fuzzy $H ¥-$-Iterative Learning LFC With Time-Varying Communication Delays and Parametric Uncertainties. IEEE Transactions on Power Systems, 34(6), 4718-4727.

Singh, O. (2017). automatic generation control of multi-area interconnected power systems using hybrid evolutionary algorithm. In Handbook of Research on Soft Computing and Nature-Inspired Algorithms (pp. 292-324). IGI Global. doi: doi:10.4018/978-1-5225-2128-0.ch010

Soni, V., Parmar, G., Kumar, M., \& Panda, S. (2016). Hybrid grey wolf optimization-pattern search (hGWOPS) optimized 2dof-Pid controllers for load frequency control (LFC) in interconnected thermal power plants. ICTACT Journal on Soft Computing, 6(3), 1244-1256.

Srinivasarathnam, C, Yammani, C., \& Maheswarapu, S. (2019). Load Frequency Control of Multi-microgrid System considering Renewable Energy Sources Using Grey Wolf Optimization. Taylor \& Francis, Smart Science. doi: 10.1080/23080477.2019.1630057

Tan, J., \& Zhang, Y. (2017). Coordinated control strategy of a battery energy storage system to support a wind power plant providing multi-timescale frequency ancillary services. IEEE Transactions on Sustainable Energy, $1-13$.

Tan, R., \& Nguyen, H. H. (2017). Modeling and mitigating impact of false data injection attacks on automatic generation control. IEEE Transactions on Information Forensics and Security, 12(7). 
Tasnin, W., \& Saikia, L. C. (2018). Maiden application of an sine-cosine algorithm optimised FO cascade controller in automatic generation control of multi-area thermal system incorporating dish-stirling solar and geothermal power plants. IET Renewable Power Generation, 12(5).

Trip, S., \& Persis, C. D. (2018). Distributed optimal load frequency control with non-passive dynamics. IEEE Transactions on Control of Network Systems, 5(3).

Tucci, M., \& Riverso, S. (2018). Line-independent plug-and-play controllers for voltage stabilization in DC microgrids. IEEE Transactions on Control Systems Technology, 26(3).

Wang, H. Z., \& Yu, T. (2015). Multi-agent correlated equilibrium Q $(\lambda)$ learning for coordinated smart generation control of interconnected power grids. IEEE Transactions on Power Systems, 30(4).

Wei, Y., Jayawardene, I., \& Venayagamoorthy, G. K. (2019). Optimal automatic generation controllers in a multiarea interconnected power system with utility-scale PV plants. IET Smart Grid, 2(4), 581-593. doi:10.1049/ iet-stg.2018.0238

Wenzel, G., Negrete-Pincetic, M., Olivares, D. E., MacDonald, J., \& Callaway, D. S. (2017). Real-time charging strategies for an electric vehicle aggregator to provide ancillary services. IEEE Transactions on Smart Grid. Advance online publication. doi:10.1109/TSG.2017.2681961

Wu, H., Ibrahim, K., Ela, E., Florita, A., \& Ibanez, E. (2016). Stochastic multi-timescale power system operations with variable wind generation. IEEE Transactions on Power Systems.

Xi, L., Li, Y., Huang, Y., Lu, L., \& Chen, J. (2018). A Novel Automatic Generation Control Method Based on the Ecological Population Cooperative Control for the Islanded Smart Grid. Hindawi Complexity, 1-17. doi:10.1155/2018/2456963

Yan, W., \& Cui, W. (2016). Pilot-bus-centered automatic voltage control with high penetration level of wind generation. IEEE Transactions on Industry Applications, 52(3).

Yatimi, H., \& Aroudam, E. (2018). Standalone Photovoltaic System with Maximum Power Point Tracking: Modeling and Simulation. International Journal of System Dynamics Applications, 7(3), 94-111. doi:10.4018/ IJSDA.2018070105

Yin, L., \& Yu, T. (2017). Artificial emotional reinforcement learning for automatic generation control of largescale interconnected power grids. IET Generation, Transmission \& Distribution, 11(9).

Yin, L., Zhang, B., Yu, T., Chen, L., \& Zheng, B. (2019). Adaptive distributed consensus protocol for automatic generation control of large-scale interconnected power systems. IEEE Access : Practical Innovations, Open Solutions, 7, 48167-48174.

Yu, Y-N., Vongsuriya, K., \& Wedman, L. N. (1970). Application of an optimal control theory to a power system. IEEE Trans. PAS, 89(1), 55-62.

Zhang, L., Luo, Y., Ye, J., \& Xiao, Y.-Y. (2017). Distributed coordination regulation marginal cost control strategy for automatic generation control of interconnected power system. IET Gener. Transm. Distrib., 11(6).1337-1344.

Zhang, X. S., \& Yu, T. (2018). Lifelong learning for complementary generation control of interconnected power grids with high-penetration renewables and EVs. IEEE Transactions on Power Systems, 33(4). 


\section{APPENDIX}

\section{Used Table List}

Table 1. Classification of AGC schemes in power system

\begin{tabular}{|l|l|}
\hline \multicolumn{1}{|c|}{ AGC Type-1 } & \multicolumn{1}{c|}{ AGC Type-2 } \\
\hline A- Robust Frequency Control & F- Impact of renewable energy in frequency regulation \\
\hline B- Robust multi-objective frequency control regulation & G- AGC scheme in wind energy source \\
\hline C- Model predictive control scheme based AGC & H- Frequency control in micro-grids \\
\hline D- AGC in deregulated environment & I- AGC based EVs \\
\hline E- Emergency conditions in AGC & J- AGC based smart grid \\
\hline & H- Some recent AI techniques in AGC \\
\hline
\end{tabular}


Table 2. Comparative literature survey on AGC schemes

\begin{tabular}{|c|c|c|c|c|c|}
\hline Reference & System Types & $\begin{array}{l}\text { No. of } \\
\text { Areas }\end{array}$ & $\begin{array}{c}\text { Generation } \\
\text { Source / Supply }\end{array}$ & $\begin{array}{c}\text { Controllers } \\
\text { Type }\end{array}$ & $\begin{array}{c}\text { Optimization } \\
\text { Techniques }\end{array}$ \\
\hline Singh (2017) & Traditional & 2 & Thermal & Fuzzy PID & hDEPSO \\
\hline Pathak et al. (2018) & Traditional & 2 & Thermal & GRC & PSO \\
\hline Marinelli et al. (2018 & Adaptive & - & Wind-Solar-Diesel & PI & Lyapunov-stable \\
\hline Rakhshani et al. (2017) & Optimal & Multi & HVDC link & ACE, VSP & SQP \\
\hline Shiva et al. (2015) & Optimal & 4 & Hydro-Thermal & IMC & QOHS-SFL \\
\hline Bansal et al. (2016) & Traditional & 2 & AC/DC link & Robust control & $\begin{array}{c}\text { State cost weighting } \\
\text { matrix } Q\end{array}$ \\
\hline Kumar et al. (2017) & Adaptive & Multi & Thermal & GRC, PID, ITAE & hGGSA-PS \\
\hline Rahman et al. (2016) & Adaptive & 4 & Thermal & $\begin{array}{l}\text { GDB, GRC, } \\
\text { 3DOF-PID }\end{array}$ & $\mathrm{BBO}$ \\
\hline Pathak et al. (2016) & Optimal & 2 & Thermal & ISE & ISE \\
\hline Tasnin et al. (2018) & Optimal & Multi & $\begin{array}{l}\text { Thermal-Solar- } \\
\text { Geothermal }\end{array}$ & SCA,SA & FOPI-FOPD \\
\hline Rahman et al. (2016) & Optimal & 3 & Thermal & 3DOF-PID & hPSO-BBO \\
\hline Saha et al. (2017) & Optimal & Multi & CCST- Thermal & GRC, I-PDF & SFS \\
\hline Bijami et al. (2017) & Optimal & 4 & Thermal-Hydro-Wind & LMI & DNC \\
\hline Hota et al. (2015) & $\begin{array}{c}\text { Optimal/ } \\
\text { Deregulated }\end{array}$ & Multi & $\begin{array}{l}\text { Thermal-Hydro- } \\
\text { Nuclear-HVDC link }\end{array}$ & PIDD & FOA \\
\hline Nanda et al. (2011) & Classical & Multi & Thermal & IDD & BFOA \\
\hline Bhatti et al. (2007) & Optimal & 1 & Thermal-Hydro-Gas & ITAE, ISE & GA \\
\hline Saikia et al. (2015) & Classical & Multi & Thermal, STPP & PID & GWO \\
\hline McNamara et al. (2018) & Model Predictive & - & MTDC & PI, MPC & MPC \\
\hline M'zoughi et al. (2018) & Model Predictive & OWC & RSC & PID, PSO & FPSOMA \\
\hline Li et al. (2018) & Model Predictive & Multi & VGT & GCD & CTQ \\
\hline Ganger et al. (2018) & Model Predictive & Multi & - & MPC & MPC \\
\hline Hu et al. (2017) & Deregulated & 3 & - & PI & DSC \\
\hline Shiva et al. (2015) & Deregulated & Multi & - & PID, SFL & QOHS \\
\hline Hasanien (2018) & Renewable & - & Wind-PVs-Waves & PID & WOA \\
\hline $\begin{array}{l}\text { Ramakrishna et al. } \\
\text { (2010) }\end{array}$ & Renewable & 1,2 & Hydro-Thermal-Gas & PID, ISE, ITAE & GA \\
\hline Li et al. (2016) & Wind Energy & Multi & Wind & PI, DGDC & DGTC \\
\hline Hasanien et al. (2017) & Wind Energy & Multi & - & PID & SOS \\
\hline Zang et al. (2016) & $\begin{array}{c}\text { Microgrid/ } \\
\text { Decentralized }\end{array}$ & Multi & Microgrid & Droop-Control & MAS, CPMS \\
\hline Li \& Zang (2016) & $\begin{array}{c}\text { Microgrid/ } \\
\text { Decentralized }\end{array}$ & Multi & Microgrid & Droop-control & EAGC \\
\hline Sadabadi et al. (2017) & $\begin{array}{c}\text { Microgrid/ } \\
\text { Decentralized }\end{array}$ & Islanded & Microgrid/DGs & QSL,3DOF & QSL \\
\hline Patterson et al. (2015) & Microgrid & Multi & $\begin{array}{l}\text { PVs, Fuel cell, } \\
\text { Batteries }\end{array}$ & - & DCDQ \\
\hline Yu et al. (2018) & Electric Vehicle & Multi & EVs, PVs, Wfs & CGC, GCD & CGC \\
\hline Manson et al. (2016) & Smart Grids & 2 & Smart Grids & C R network & C R network \\
\hline
\end{tabular}


Table 3. List of used artificial intelligent/soft computing techniques for references

\begin{tabular}{|c|c|}
\hline $\begin{array}{c}\text { Algorithm (AI/Soft computing } \\
\text { Techniques) }\end{array}$ & References \\
\hline ACO (Ant colony optimization) & Kaliannan et al. (2016) \\
\hline ASOS ( Application of adaptive-SOS) & Sahu et al.(2018) \\
\hline $\begin{array}{l}\text { HPSO (hybrid pattern search-biogeography } \\
\text { based optimization) }\end{array}$ & Sinha et al. (2016) \\
\hline $\begin{array}{l}\mathrm{CEQ}(\lambda) \text { (Multi-agent correlated } \\
\quad \text { equilibrium learning) }\end{array}$ & Wang et al. (2015) \\
\hline hDEA (hybrid evolutionary algorithm) & Singh (2017) \\
\hline $\begin{array}{l}\text { hDEPSO ( Hybrid differential evolution } \\
\text { particle swarm optimization) }\end{array}$ & Sahu et al.(2014) \\
\hline $\begin{array}{l}\text { ERL ( Artificial emotional reinforcement } \\
\text { learning) }\end{array}$ & Yu et al. (2017) \\
\hline FA ( Firefly Algorithm) & $\begin{array}{l}\text { Pradhan, et al., (2016); Padhana, et al., (2014); \& Jagatheesan, et al., } \\
\text { (2017) }\end{array}$ \\
\hline FO (Fruit fly optimization) & Hota et al. (2015) \\
\hline $\begin{array}{l}\text { hGGSA-PS } \\
\text { (Hybrid adaptive 'gbest'-guided } \\
\text { gravitational search and } \\
\text { pattern search algorithm) }\end{array}$ & Kumar, et al.,(2017); \& Khadanga, et al., (2017) \\
\hline GOW ( Grey wolf optimization) & $\begin{array}{c}\text { Saikia, et al., (2015); Srinivasarathnam, et al., (2019); Padhy, et } \\
\text { al.,(2017); Singh, et al., (2017); Mohanty, et al., (2017); Lal,et al., (2016); } \\
\text { \& Soni, et al. (2016) }\end{array}$ \\
\hline MGOW (Modified Grey wolf optimization) & Padhy, et al., (2017) \\
\hline $\begin{array}{l}\text { QOGWO( Quasi-Oppositional Grey Wolf } \\
\text { optimization) }\end{array}$ & Guha, et al., (2016) \\
\hline KHA ( Krill herd algorithm) & Roy, et al., (2016) \\
\hline MFO ( Moth-flame optimization) & Hota, et. al., (2017) \\
\hline PSO ( particle swarm optimization) & Singh, et al., (2012); \\
\hline SSO ( Stochastic search optimization) & Saha, et al., (2017) \\
\hline $\begin{array}{l}\text { QOHS ( Quasi-oppositional harmony } \\
\text { search) }\end{array}$ & Mukherjee, et al., (2015); \& Shiva, et al., (2016) \\
\hline WOA ( Whale optimisation algorithm) & Hasanien (2018) \\
\hline $\begin{array}{c}\text { TLBO ( Teaching learning based } \\
\text { optimization ) }\end{array}$ & Panda, et al., (2016) \\
\hline
\end{tabular}


Ashwini Kumar currently pursues Ph.D in Electrical Engineering Department from School of Engineering, Gautam Buddha University, Greater Noida, Gautam Buddha Nagar, U.P. (201312), India. He has fine experience in teaching and research field of electrical engineering. He has done B. Tech with Electrical and Electronics Engineering and $M$. Tech with Electrical Engineering. His area of interest is electrical power system, power system operation and control, and micro-grid. He has published different research papers in international Journals and has presented many papers in international conferences.

Omveer Singh has a rich experience of teaching as well as research. Currently, he is an assistant professor (senior scale) in Electrical Engineering Department, School of Engineering, Gautam Buddha University, Greater Noida, U.P. (201312), India. He did his B.Tech and M.Tech from Dayalbagh Educational Institute, Uttar Pradesh, India. Also, he achieved PhD degree from Jamia Millia Islamia University, New Delhi, India. He has published many research articles in the peer refereed journals and conferences. He is supervising several PhD candidates. He has diversified research interests in the areas of electrical power systems, soft computing techniques, and hybrid renewable power generation resources. 